\title{
OBSERVATIONS ON CERTAIN MANIFESTATIONS OF CIRCULATORY CONGESTION PRODUCED IN DOGS BY RAPID INFUSION
}

\author{
BY ANDREW YEOMANS, RENO R. PORTER, AND ROY L. SWANK \\ (From the Departments of Medicine and Pathology, Harvard Medical School, and the Medical
}

Clinic of the Peter Bent Brigham Hospital, Boston)

(Received for publication June 11, 1942)

The intravenous injection of fluids has been frequently utilized to study the dynamics of the circulation. The purpose of this study is to describe the response of intact dogs to such injections. In a previous paper (Swank, Porter and Yeomans (1)); the infusion method described in this paper was used to study changes in the adaptability of the cardiovascular system in thiamin deficient dogs.

\section{METHODS}

The following experimental procedure was finally adopted. Non-pregnant female dogs, weighing between 10 and $18 \mathrm{kgm}$., were used. After fasting 18 to 24 hours, the animal to be studied was anesthetized with an intravenous solution of alpha chloralose (100 to $110 \mathrm{mgm}$. per $\mathrm{kgm}$. of body weight) or pentobarbital sodium (33 mgm. per kgm.), and placed on its back on a dog board, with its legs lightly secured. Number 18 Lindeman needles were placed in one jugular and one femoral vein, and a glass catheter was placed in the bladder. The needle in the femoral vein was attached, by a side-arm syringe and rubber tubing, to a copper coil kept at a constant temperature by a water bath. The infusion fluid flowed through this coil from a glass reservoir which could be read accurately to $10 \mathrm{cc}$. The speed of flow of the infusion was regulated by raising or lowering the reservoir. The needle in the jugular vein was attached to a manometer containing $1 / 6$ molar sodium carbonate solution. This solution was allowed to run into the jugular needle at the rate of approximately 4 to $5 \mathrm{cc}$. per hour, as described by Trendelenburg (2). This prevented the blood from clotting and allowed the venous pressure to be accurately indicated throughout the experiment. Since it would have been necessary to sacrifice each animal to determine accurately the level of the right auricle, the back of the animal was arbitrarily chosen as the zeropoint for venous pressure. This seemed sufficient for our purpose as we were interested in comparing the results of different infusions in the same animal, and in changes in venous pressure rather than in absolute values. A rubber tube of $5 \mathrm{~mm}$. internal diameter was placed in the dog's trachea to assure a free air passage.

After the venous pressure and heart rate had been recorded several times, the infusion was begun and run for 30 minutes by stop watch, at the rate of 2.5 to 5.0 cc. per $\mathrm{kgm}$. per minute. At 2 minute intervals during ${ }^{1}$ the infusion, the jugular venous pressure, the heart rate, and the amount of the infusion were read and recorded. The urine output was measured at 10 minute intervals. After the infusion was discontinued, venous pressure, cardiac rate, and urine output were observed until the venous pressure returned to, or nearly to, normal. The length of the infusion period and its volume were chosen because they were found to approach the limit of tolerance in healthy dogs. Moreover, this period allowed the venous pressure in normal dogs to become adjusted to the increased plasma volume. With alpha chloralose, the anesthesia was quite satisfactory throughout the entire experiment, whereas with pentobarbital sodium it was frequently necessary to give additional anesthetic toward the end of the infusion.

Arterial pressures in $\mathrm{mm}$. $\mathrm{Hg}$, when taken, were determined directly, by inserting a needle into the femoral artery. Clotting in the needle was avoided by allowing a small amount of $1 / 6$ molar sodium carbonate to run into the artery continuously (2).

During some of the infusion experiments the following supplementary data were obtained:

(1) The oxygen consumption was determined with a Benedict-Roth apparatus. This was connected to the dog by means of a Blalock mask (3).

(2) Measurements of the cardiac output were obtained by means of the Fick formula. Blood was drawn under oil simultaneously from the right heart and a femoral artery. The heart was auscultated during this procedure and gross changes in its rate were noted. The oxygen content and capacity of the blood samples were immediately determined in duplicate by the method of Van Slyke and Neill (4).

(3) Plasma volume was measured by the method of Gibson and Evans (5) using the azo dye, Evans Blue, and the spectrophotometer.

(4) Variations in cardiac rhythm and sounds were noted by auscultation, and in suitable cases recorded by electrocardiograms or phonocardiograms.

(5) Changes in the heart size during infusion were determined by repeated $x$-rays using a standard distance of 6 feet.

1 The advantage in accuracy, of avoiding interruption of infusion while reading pressure, which the use of a separate vein provides, may be seen in Figure 1. Discontinuance of infusion for one minute at $\mathrm{A}$ and $\mathrm{B}$ caused a large fall in pressure. 
(6) Measurements of the portal venous pressure were recorded directly in 2 experiments. In one, the abdomen was opened and the needle inserted in the portal vein; in the other, the needle was inserted in a splenic vein of an animal whose spleen had been previously extraperitonealized under the skin.2

(7) The total serum proteins were determined by the Kjeldahl method with Nesslerization, in blood drawn just prior to and at the end of infusion.

(8). In one infusion experiment, the pulmonary venous pressure was measured directly, by means of a catheter inserted into the left auricular appendage.

\section{OBSERVATIONS}

More than 100 infusions, in 17 dogs, form the basis of the following report. The venous pressure, heart rate, and volume of flow of the infusion fluid were recorded in every experiment. The additional observations mentioned above were collected to an adequate extent. Experiments were also devised to permit measurements of venous pressure in the portal and pulmonary systems.

Peripheral venous pressure. The intravenous injection of fluid at rates of 2 to $6 \mathrm{cc}$. per $\mathrm{kgm}$. per minute caused the venous pressure to rise in all instances. Examples of this are shown in Figures 1 to 4 . During the first 10 or 15 minutes

2 For this operation we are indebted to Dr. J. E. Dunphy.

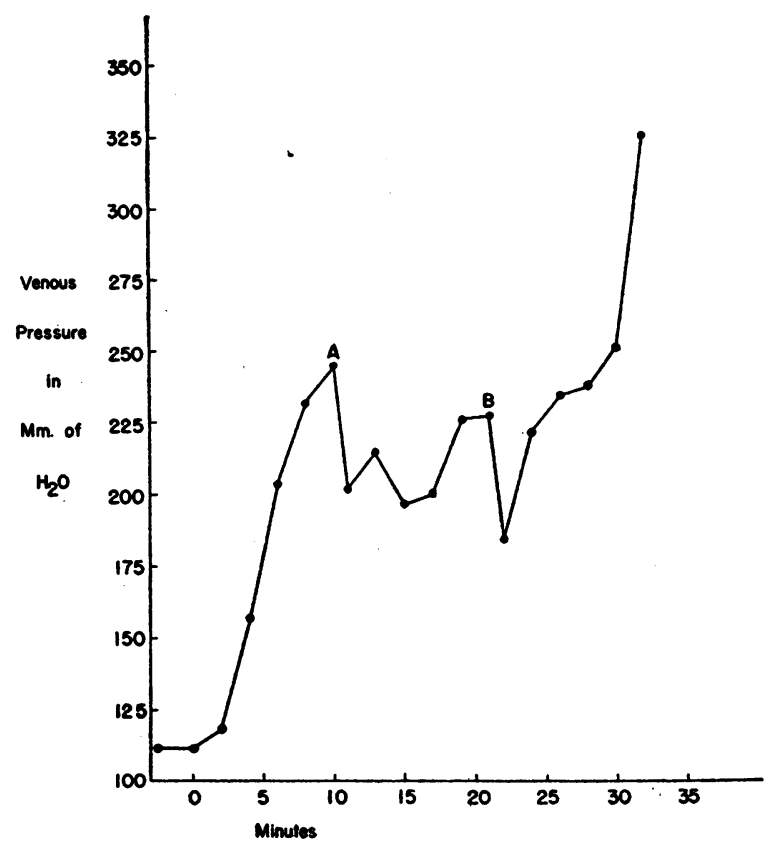

Fig. 1. Represents an Infusion of 10 per cent Dextrose and Saline at a Rate of $4.7 \mathrm{cc}$. PER KGM. PER MINUTE

Pulmonary edema with death occurred at the highest point reached in the venous pressure curve. The infusion was interrupted for one minute at points $A$ and $B$.

of infusion, the rise was rapid and uniform, but thereafter progressively slower until about the last 10 minutes of injection, during which the

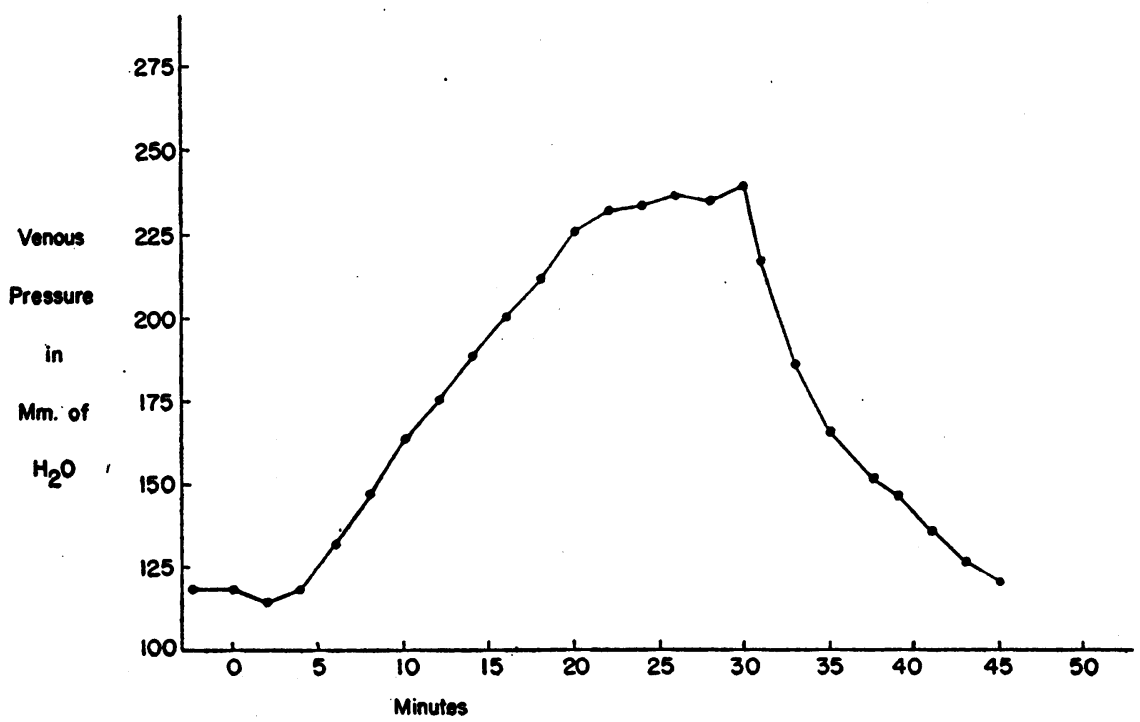

Fig. 2. Results of Saline Infusion in Dog 10 at a Rate of 6.2 cc. PER KGM. PER MINUTE 


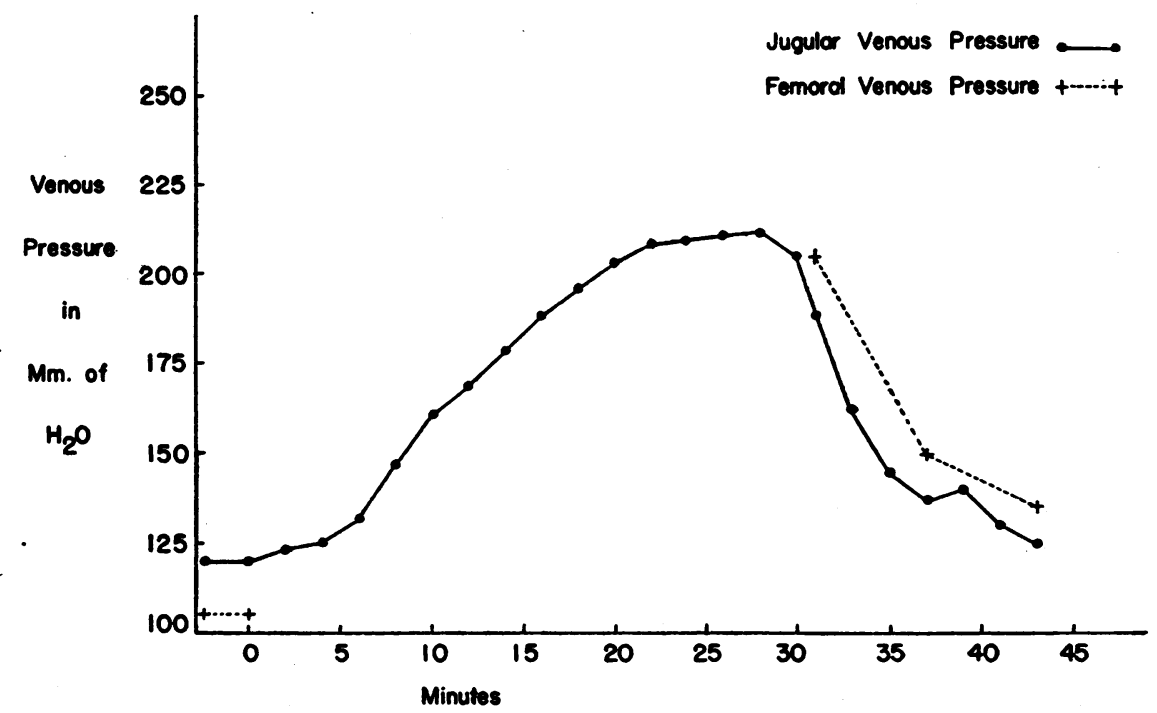

Fig. 3. Results of Saline Infusion in Dog 10 at a Rate of 5.7 cc. PER KGM. PER MINUTE

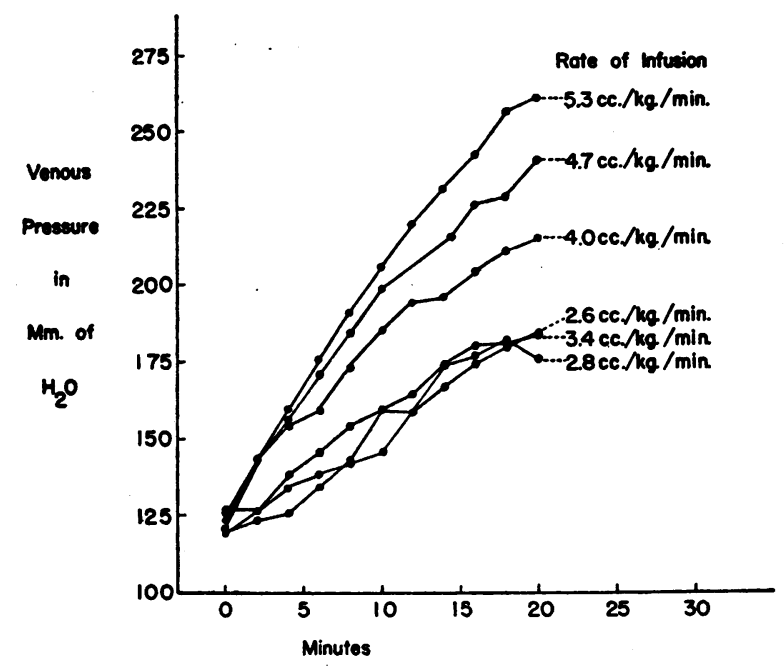

Fig. 4. Results of Infusions in Dog 10 at Varying Rates of Flow

venous pressure usually changed but little. Figures 2 and 3 show the characteristic record of tapering rise to a plateau. The venous pressure fell promptly, immediately after the infusion was discontinued, and then more slowly as the preinfusion venous pressure was approached. In some experiments, venous pressures were recorded simultaneously in the superior and inferior caval systems, during the period immediately following the infusion. Usually, the femoral pres- sure fell more slowly than the jugular (Figures 3,10 , and 11).

The shape of the venous pressure curve was influenced markedly by the speed of infusion. In general, it can be said that the greater the speed of infusion, the more rapid the rise in venous pressure. The changes shown in Figure 4 are fairly representative, although variations from this relationship were not uncommon.

Solutions of normal saline ( 0.85 per cent), and of 10 per cent dextrose in normal saline, were used to determine the effects of an isotonic and hypertonic infusion fluid upon the venous pressure. Table I shows that hypertonic glucose solutions caused the venous pressure to rise very much faster than did normal saline. In fact, it was usu-

TABLE I

Results of venous pressure measurements in the same dog, infused with saline and dextrose solutions at the same rate of flow

Dog No. 9 (Normal)

\begin{tabular}{|c|c|c|c|}
\hline Solution & $\begin{array}{l}\text { Initial } \\
\text { venous } \\
\text { pressure }\end{array}$ & $\begin{array}{c}\text { Venous } \\
\text { pressure } \\
\text { after } \\
10 \text { minutes } \\
\text { infusion }\end{array}$ & $\begin{array}{c}\text { Increase } \\
\text { over } \\
\text { initial } \\
\text { venous } \\
\text { pressure }\end{array}$ \\
\hline $\begin{array}{l}0.85 \text { per cent saline } \\
10 \text { per cent dextrose in } \\
\text { saline }\end{array}$ & $\begin{array}{c}m m . H, O^{*} \\
123 \\
129\end{array}$ & $\begin{array}{c}m m . H 20 * \\
175 \\
253\end{array}$ & $\begin{array}{l}\text { per cent } \\
42.5 \\
96.1\end{array}$ \\
\hline
\end{tabular}

* Zero point at skin of dog's back as dog lies on dog table. 
TABLE II

Comparison of jugular and portal venous pressures during saline infusions

\begin{tabular}{|c|c|c|c|c|}
\hline \multirow{2}{*}{ Anesthesia } & \multicolumn{2}{|c|}{ Abdomen open } & \multicolumn{2}{|c|}{ Extraperitonealized spleen } \\
\hline & \multicolumn{2}{|c|}{ Pentobarbital-sodium } & \multicolumn{2}{|c|}{ Alpha chloralose } \\
\hline $\begin{array}{l}\text { Rate of } \\
\text { infusion }\end{array}$ & \multicolumn{2}{|c|}{$3.8 \mathrm{cc}$. per $\mathrm{kgm}$. per minute } & \multicolumn{2}{|c|}{$4.5 \mathrm{cc}$. per $\mathrm{kgm}$. per minute } \\
\hline Time & $\begin{array}{l}\text { Jugular } \\
\text { venous } \\
\text { pressure }\end{array}$ & $\begin{array}{c}\text { Portal } \\
\text { venous } \\
\text { pressure }\end{array}$ & $\begin{array}{c}\text { Jugular } \\
\text { venous } \\
\text { pressure }\end{array}$ & $\begin{array}{c}\text { Portal } \\
\text { venous } \\
\text { pressure }\end{array}$ \\
\hline $\begin{array}{c}\text { minutes } \\
0\end{array}$ & $\begin{array}{c}m m . H_{2} \mathrm{O} \\
157\end{array}$ & $\begin{array}{c}m m . \mathrm{H}_{2} \mathrm{O} \\
194\end{array}$ & $\begin{array}{c}m m . \mathrm{H}_{2} \mathrm{O} \\
138\end{array}$ & $\begin{array}{c}m m . H 2 O \\
280\end{array}$ \\
\hline 2 & 165 & 198 & 163 & 298 \\
\hline 4 & 167 & 204 & 188 & 307 \\
\hline 6 & 168 & 213 & 197 & 313 \\
\hline 8 & 168 & 221 & 225 & 320 \\
\hline 10 & $168^{*}$ & $230 *$ & 250 & 335 \\
\hline \multirow{7}{*}{$\begin{array}{l}12 \\
13 \\
14 \\
15 \\
16 \\
17 \\
18 \\
19 \\
20 \\
21 \\
22\end{array}$} & \multirow{2}{*}{170} & \multirow{2}{*}{243} & 260 & 335 \\
\hline & & & 275 & 353 \\
\hline & 171 & 270 & 288 & 357 \\
\hline & \multirow{3}{*}{$\begin{array}{l}179 \\
184\end{array}$} & \multirow[b]{2}{*}{302} & & \\
\hline & & & 291 & 301 \\
\hline & & \multirow{2}{*}{$302^{*}$} & 308 & 373 \\
\hline & $183^{*}$ & & 324 & 388 \\
\hline 24 & 190 & 301 & 330 & 398 \\
\hline 26 & 187 & 300 & 340 & 413 \\
\hline 28 & 189 & 300 & 340 & 408 \\
\hline 30 & 196 & 303 & $335 \dagger$ & $408 t$ \\
\hline \multirow{2}{*}{$\begin{array}{l}31 \\
32 \\
33\end{array}$} & $\dagger$ & $t$ & \multirow{2}{*}{$\begin{array}{ll}\cdot & 258\end{array}$} & 361 \\
\hline & & & & 338 \\
\hline $\begin{array}{l}35 \\
38 \frac{1}{2}\end{array}$ & \multirow{3}{*}{$\begin{array}{l}162 \\
157\end{array}$} & \multirow{3}{*}{$\begin{array}{l}269 \\
262\end{array}$} & 237 & 328 \\
\hline $41^{\circ}$ & & & 202 & 300 \\
\hline 45 & & & 193 & 282 \\
\hline
\end{tabular}

* Infusion stopped for 1 minute.

$\dagger$ Infusion completed.

ally necessary to interrupt dextrose-in-saline infusions because of the very alarming venous pressures which were apt to develop. The indication for caution in therapeutic use of this hypertonic solution is evident.

Portal pressures. The data concerning pressures in the portal system during infusion were obtained from 2 experiments (Table II). In each of these, both the initial and final portal venous pressures were higher than the initial or final peripheral venous pressures, although, in one instance, the portal pressure rose more than the systemic venous pressure, and in the other, it rose somewhat less. A high portal pressure was also evidenced by the development of a marked swelling of the abdomen and enlargement of the liver during all infusions, and swelling of the spleen in the 2 cases in which the size of this organ could be determined.

TABLE III

Increase in plasma volume and output of urine during and after infusion

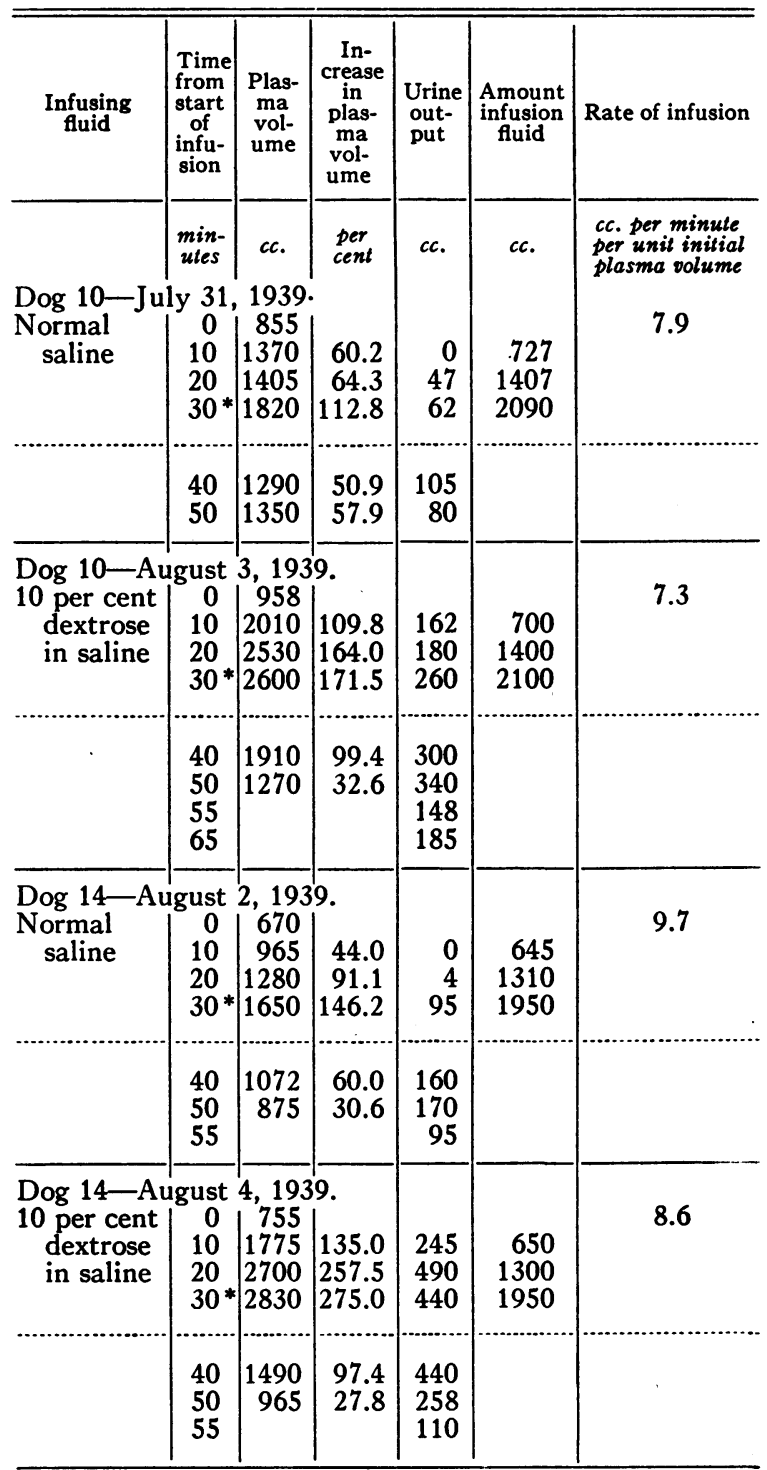

* End of infusion, which was interrupted for one minute at 10 and 20 minutes. 


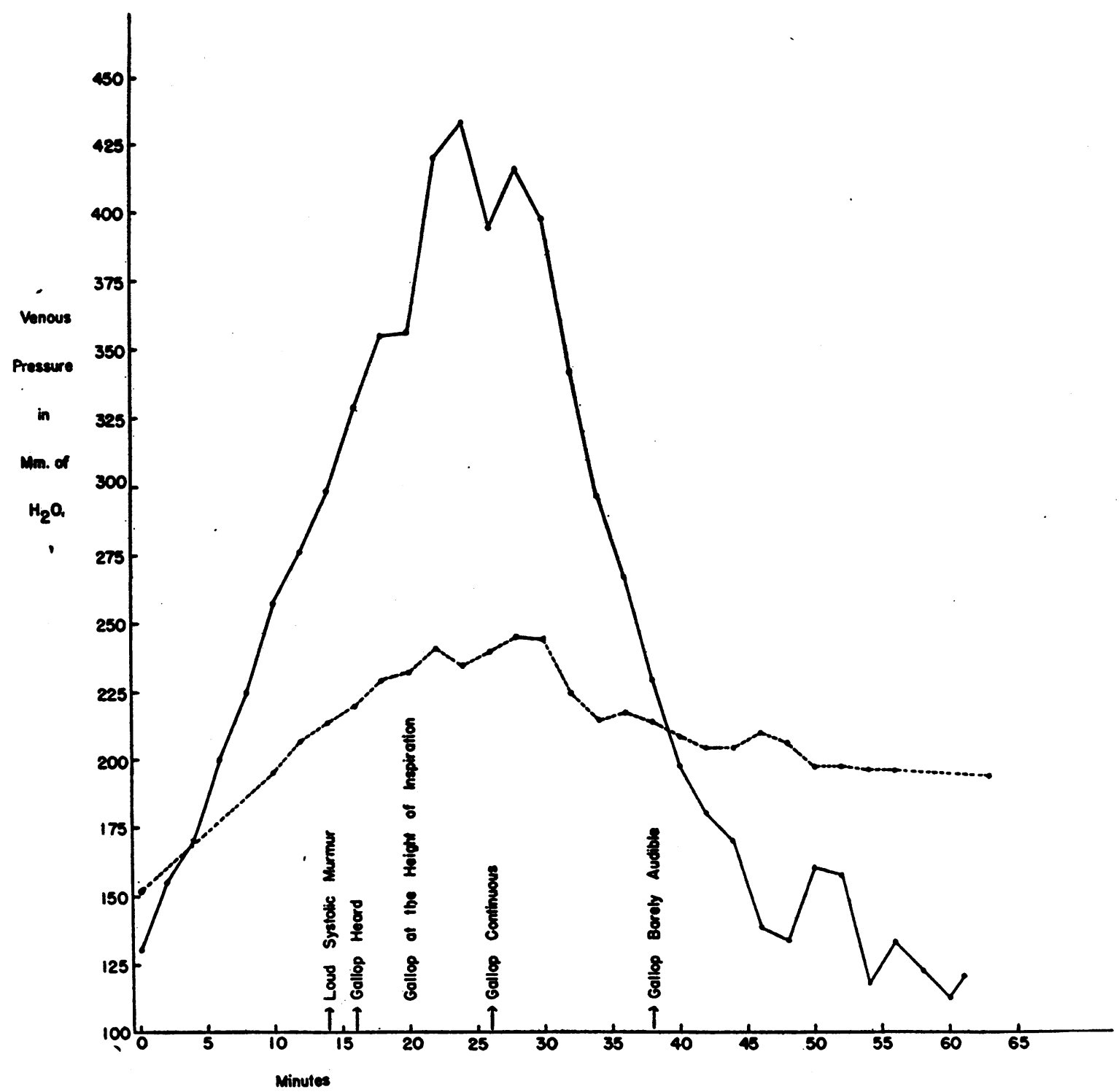

Fig. 5. Measurements of Left Auricular Pressure and Peripheral Venous Pressure

Continuous line represents the left auricular pressure. Interrupted line represents the femoral venous pressure. Time of infusion is 30 minutes.

Pulmonary venous pressure. ${ }^{3}$ The effect of infusion on the pulomnary circuit was studied in one experiment (Figure 5). Under alpha chloralose anesthesia, a rubber catheter was stitched into the left auricular appendage and the usual manometer attached. After the left lung had been reexpanded, an infusion of saline was given, and the peripheral venous and left auricular pressures

\footnotetext{
3 We are indebted to Dr. Robert Gross for the surgical part of this experiment.
}

were recorded. Before the infusion, the auricular pressure rose and fell some $80 \mathrm{~mm}$. with expiration and inspiration, respectively. After the auricular pressure had risen as a result of infusion, these marked respiratory excursions gradually decreased, but appeared again, following the cessation of infusion. The graph of this experiment shows that the pressure in the pulmonary circuit rose more rapidly and to a much higher level than was observed in the peripheral venous circuit dur- 
ing infusions of the same speed. In this experiment, no pulmonary râles were heard, but a systolic murmur and a gallop rhythm appeared.

Plasma volume: ${ }^{4}$ Representative studies of the plasma volume changes during infusion are shown in Table III and Figure 6. Calculations of the total blood volume are not recorded, as the red blood cell volume during and after infusion fluctuated markedly, probably because of an uneven dilution of the red blood cells which occurred during the infusion.

The infusions of 10 per cent dextrose in saline not only produced a much greater increase in plasma volume than did saline alone, but did so even when the infusions were slower. Apparently this very hypertonic solution caused fluid to be drawn into the blood stream from outside the vascular system in addition to that injected, since in $\operatorname{dog} 14$ the total amount of injected fluid at the termination of infusion was less than the fluid

4 We wish to express our appreciation to Dr. John G. Gibson, II, for his aid in these studies. which had been added to the initial plasma volume, and in $\operatorname{dog} 10$, an addition to the plasma volume of $1572 \mathrm{cc}$. had taken place, whereas but $1400 \mathrm{cc}$. of fluid had been injected at the twentieth minute of infusion. Another indication of this very marked increase in the blood volume is to be found in the alarming rise in venous pressure, mentioned before. Both during and after 10 per cent glucose in saline infusions, a tremendous diuresis occurred. Usually, the plasma volume returned to normal more rapidly after glucose than after saline injections.

Serum proteins. The total serum proteins were decreased by all infusions (see Table IV). At rates of flow between 55 and $70 \mathrm{cc}$. per minute, the total protein content of the serum was almost halved. The non-protein nitrogen also fell during infusions, but less than the proteins.

Heart rate. In dogs anesthetized with pentobarbital sodium, the heart rate was usually rapid and quite variable, both before and during infusion. The sinus arrhythmia was never marked. There was a tendency, however, for the rate to

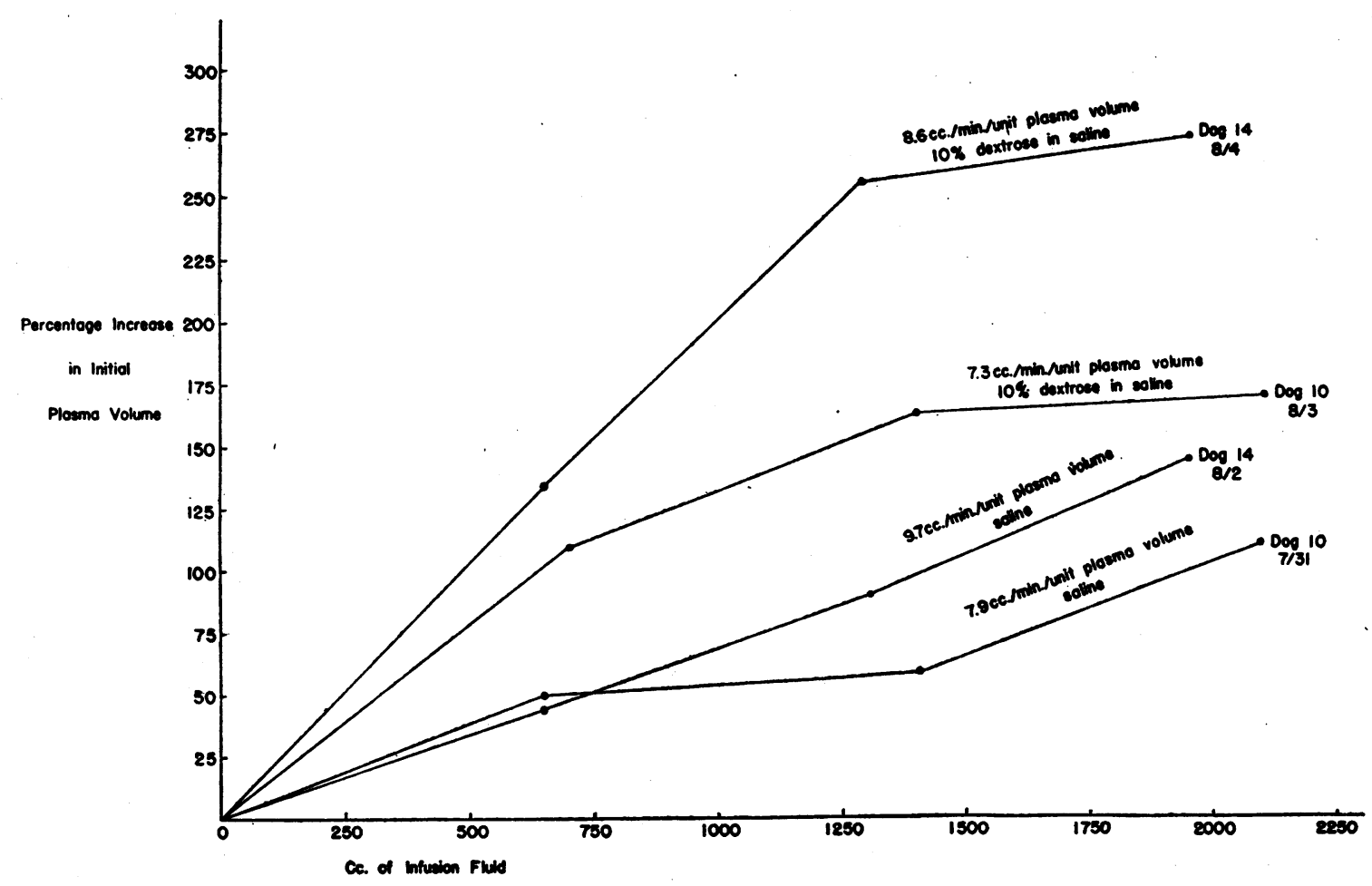

Fig. 6. Changes in the Plasma Volume Occurring as a Result of Intravenous Infusions with Dextrose in Saline and with Saline Alone 
TABLE IV

Effect of infusion upon the serum proteins in dogs

\begin{tabular}{|c|c|c|c|c|c|c|}
\hline \multirow{2}{*}{$\begin{array}{c}\text { Dog } \\
\text { number }\end{array}$} & \multicolumn{2}{|c|}{ Serum protein } & \multicolumn{2}{|c|}{$\begin{array}{l}\text { Non-protein } \\
\text { nitrogen }\end{array}$} & \multirow{2}{*}{$\begin{array}{c}\text { Rate of } \\
\text { infusion }\end{array}$} & \multirow{2}{*}{ Weight } \\
\hline & $\begin{array}{c}\text { Before } \\
\text { infusion }\end{array}$ & $\underset{\text { infusion }}{\text { After }}$ & $\begin{array}{c}\text { Before } \\
\text { infusion }\end{array}$ & $\begin{array}{c}\text { After } \\
\text { infusion }\end{array}$ & & \\
\hline & \multicolumn{2}{|c|}{ grams per $100 \mathrm{cc}$. } & \multicolumn{2}{|c|}{ mgm. per $100 \mathrm{cc}$. } & $\begin{array}{l}c c \text { per } \\
\text { minute }\end{array}$ & kgm. \\
\hline $\begin{array}{l}17 \\
10 \\
10 \\
15 \\
15\end{array}$ & $\begin{array}{l}5.2 \\
5.8 \\
5.2 \\
6.0 \\
6.1\end{array}$ & $\begin{array}{l}3.3 \\
3.0 \\
3.1 \\
3.1 \\
3.1\end{array}$ & $\begin{array}{l}20 \\
41 \\
34 \\
40\end{array}$ & $\begin{array}{l}14 \\
31 \\
25 \\
30\end{array}$ & $\begin{array}{l}55 \\
65 \\
70 \\
62 \\
60\end{array}$ & $\begin{array}{l}12.2 \\
18.8 \\
18.8 \\
18.4 \\
18.4\end{array}$ \\
\hline
\end{tabular}

increase toward the termination of infusion and sometimes it exceeded 200 beats a minute.

With chloralose, the heart rate was more often relatively slow preceding the infusion, and the sinus arrhythmia, normally marked in dogs, was unchanged. In the majority of experiments, the heart rate increased within the first 2 minutes of injection, and continued to increase throughout the infusion, to reach a rate approximately 40 to 70 beats faster than was observed before infusion.

Arterial blood pressure. The recording of the mean arterial blood pressure, during 5 infusions on 4 animals, showed a rise of 10 to $20 \mathrm{~mm}$. of mercury during the latter part of the infusion, in
4 instances. During 3 injections, this rise was preceded during the first 16 minutes by a slight temporary fall (about $10 \mathrm{~mm}$. of mercury) in the mean pressure.

Cardiac output. The cardiac output was determined, during infusion on 17 occasions, in 6 normal dogs under chloralose anesthesia. In Figure 7 , the increase in cardiac output is plotted against the duration of the infusion. This demonstrates that the greatest increase in cardiac output occurred during the first few minutes of the infusion. In 2 instances, it was shown by successive cardiac outputs taken during the same infusion that there was a slight further increase in cardiac output during the latter part of the infusion period. Isolated studies on different dogs on different days (Figure 8) showed that the cardiac output increased to a variable degree throughout the infusion, and was in no clear way related to the height of the venous pressure. This increased cardiac output persisted for as long as 10 minutes after the completion of the infusion, although the venous pressure had returned nearly to normal by that time.

Arrhythmias and murmurs during infusion. During infusion, there was a disappearance of the

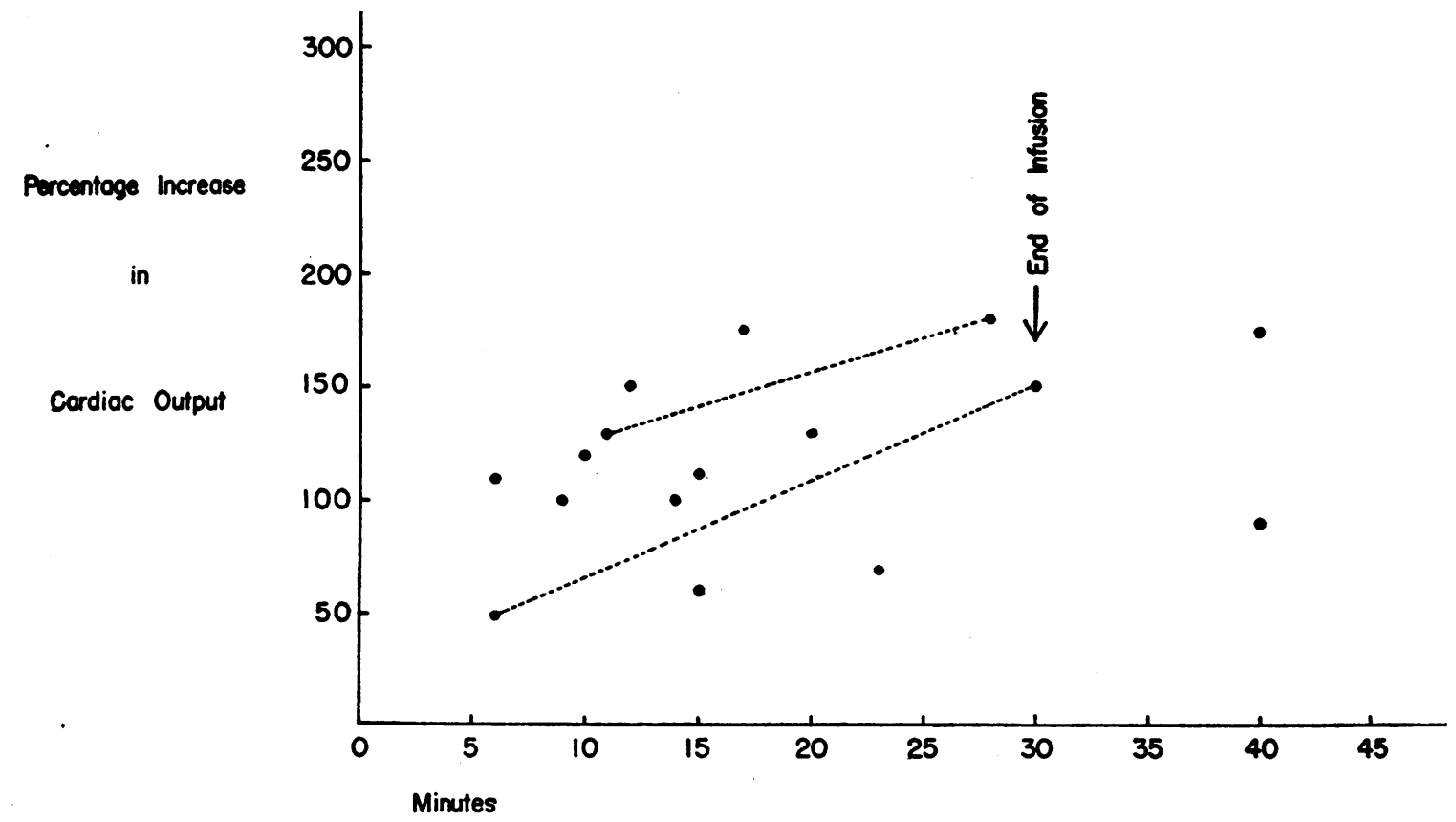

Fig. 7. The Percentage Increase in the Output of the Heart with Intravenous Infusion The interrupted lines connect measurements made on the same animal at two points during one infusion. 


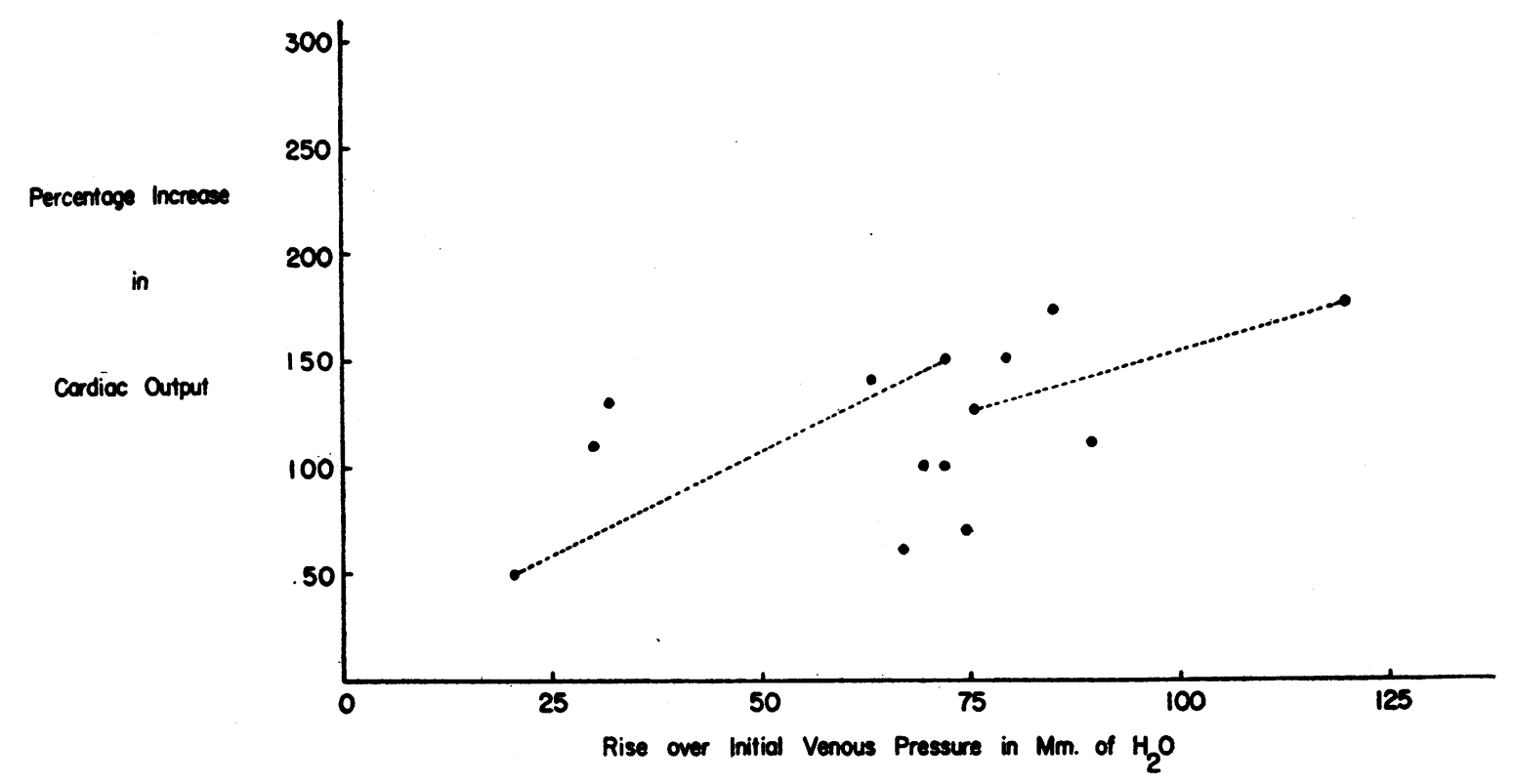

Fig. 8. Represents the Relation Between the Increase of Venous Pressure Occurring During Infusion and the Percentage Increase in Cardiac Output

Interrupted lines connect measurements made on the same animal at two points during one infusion.

sinus arrhythmia normally present in alpha chloralose anesthetized dogs. Extrasystoles were noted only once during infusion.

In 4 dogs that had each received 7 to 15 infusion tests, systolic murmurs were observed during basal conditions. This suggests that the heart had become affected permanently by this procedure. A systolic murmur, usually heard best to the left of the sternum, almost always developed during an infusion. Although the venous pressure was always elevated to some degree when the murmur appeared, it could not be correlated with any specific elevation in this pressure. Neither could it be correlated with a rise in heart rate, since in some experiments with pentobarbital sodium, the murmur appeared when the cardiac rate was slower than before infusion. During the recovery period, the murmur usually disappeared at about the level of venous pressure where it was first noted during the infusion. Despite this relationship, it is probable that the murmur is more directly associated with changes in the pulmonary than in the peripheral venous pressures.

Usually, during the second 10 minutes of infusion and shortly after the appearance of the systolic murmur, a gallop rhythm was noted. The additional third sound was first audible during the height of inspirations and soon after throughout the respiratory cycle. By means of a phonocardiogram, with simultaneous jugular pulse and electrocardiogram, the presence of this extra sound was clearly established (Figure 9). Careful examination of the control record (A) reveals that no sound was recorded during diastole just before the occurrence of the first heart sound. During the infusion, when a gallop rhythm could be clearly auscultated (B), a new sound was recorded, just before the first heart tone. This seems to identify the gallop rhythm as presystolic in time.

No relationship was found between heart rate and the appearance of the gallop rhythm in dogs anesthetized by pentobarbital sodium. Indeed, in 11 of a series of 19 infusions, the heart rate was below the preinfusion rate at the time the gallop rhythm first became audible. The slowest heart rate associated with a gallop rhythm in pentobarbital anesthetized dogs was 112 beats per minute, the most rapid, 204 beats per minute. In these same animals, the venous pressure was elevated between 20 and $130 \mathrm{~mm}$. of water. With alpha chloralose as an anesthetic, the gallop rhythm was noted only when the heart rate was increased over basal levels, e.g., to between 134 and 180 beats per minute, and usually, when the venous 
pressure was increased 25 to $90 \mathrm{~mm}$. of water. In both anesthetics, it is probable that the gallop general, it may be said that when the gallop rhythm appeared with a heart rate in the lower range, the venous pressure was more frequently in the upper range; when the heart rate was in the upper range, the venous pressure was in the lower range. With rhythm, like the systolic murmur, was related more directly to changes in the pulmonary than in the peripheral venous pressure.

Heart size during infusion. X-rays of the heart during infusion were made in 4 instances on 2

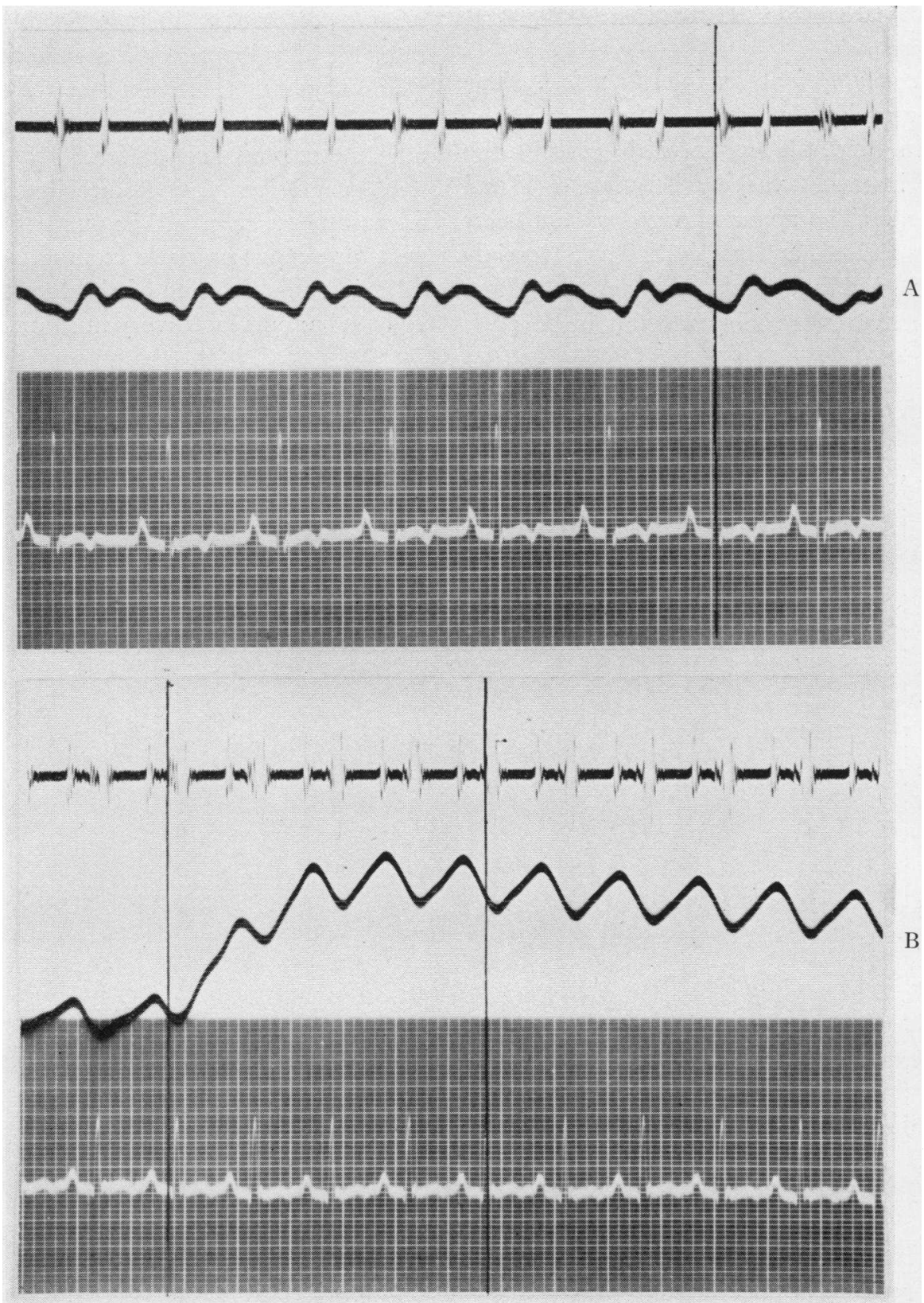

Fig. 9. Represents the Appentance of a Third Heart Sound During an Intravenous Infusion

A is normal control, B, during infusion. 
dogs. In 2 of the experiments, the anesthetic was pentobarbital sodium, and in 2 others, alpha chloralose. There was a progressive increase in heart diameter during infusion, the greatest being $1 \mathrm{~cm}$. The diameter of the heart appeared to increase more rapidly and to a greater extent under pentobarbital sodium, but this could not be substantiated by careful measurements of the circumference of the heart.

Oxygen consumption during infusion. The oxygen consumption during an infusion generally increased somewhat, the amount of increase in the majority of instances varying between +1 and +13 per cent. The apparent vigor of the heart action was increased, and respiration was accelerated, although slightly diminished in depth. These heightened activities probably account in part for the moderate increase in oxygen consumption noted in some experiments.

\section{DISCUSSION}

By rapidly increasing the plasma volume, many of the phenomena observed in patients with congestive heart failure (e.g., a rise in peripheral venous pressure, an increase in the heart size and rate, the development of a systolic murmur and gallop rhythm, and swelling of the abdomen, liver, and spleen) were produced in the dog. It is significant that our dogs differed from most patients with congestive heart failure in their ability $(a)$ to maintain a high cardiac output and $(b)$ to prevent the venous pressure from rising above a critical level; this, in spite of the fact that the plasma volume had increased very much more than it does

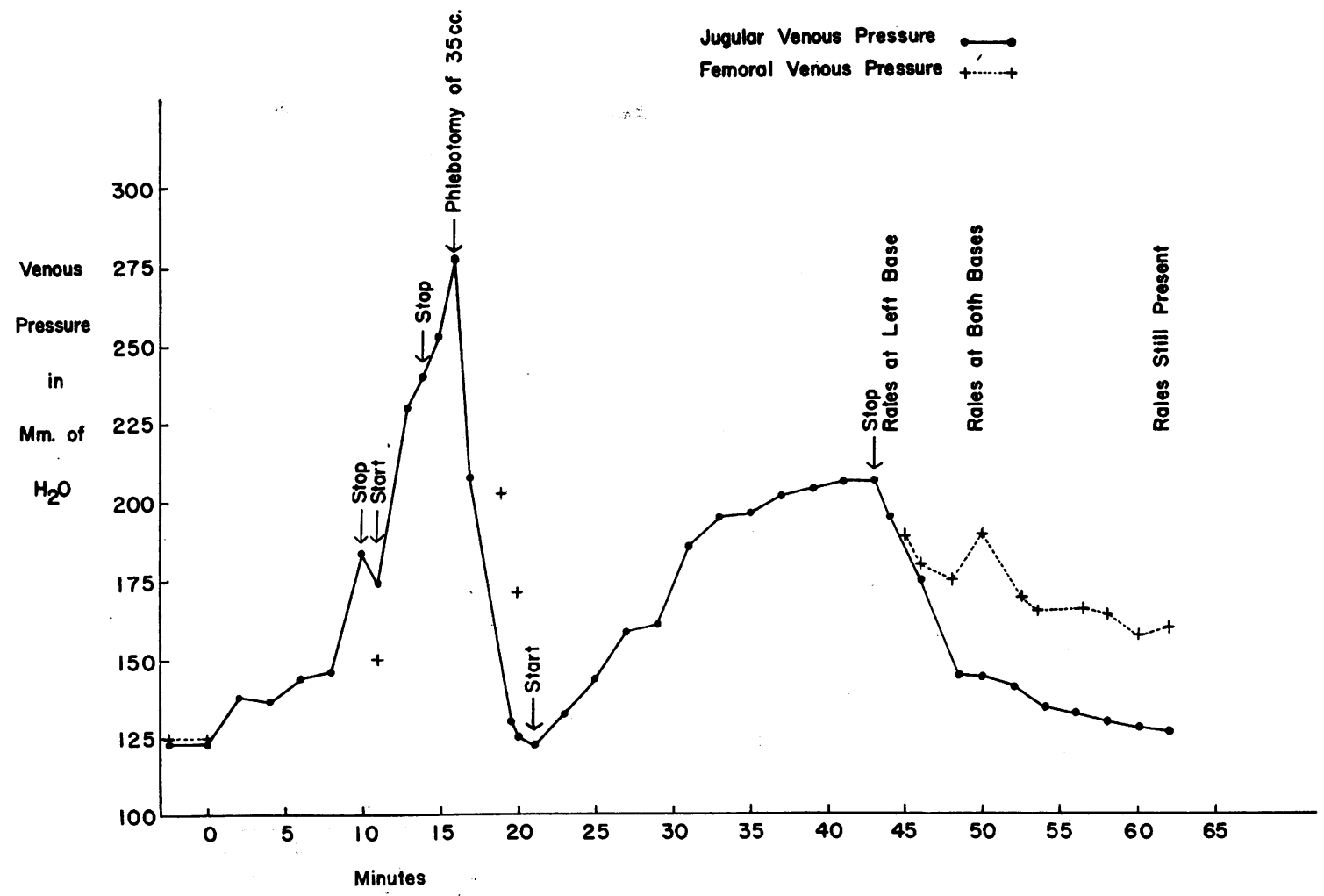

Fig. 10. The Effect of a Phlebotomy Carried Out During Infusion with 10 per cent Dextrose in Normal Saline

This was performed as emergency treatment because of rapidly rising peripheral venous pressure. In spite of the rapid fall of pressure to normal following phlebotomy and lower curve when the infusion was again continued, evidences of high pressure in the pulmonary circuit developed. The arrows marked "stop" and "start" indicate temporary interruptions of the infusion. Rate of infusion during the first 14 minutes was $4.2 \mathrm{cc}$. per kgm. per minute. Afterwards it was continued at 3.3. cc. per kgm. per minute. 


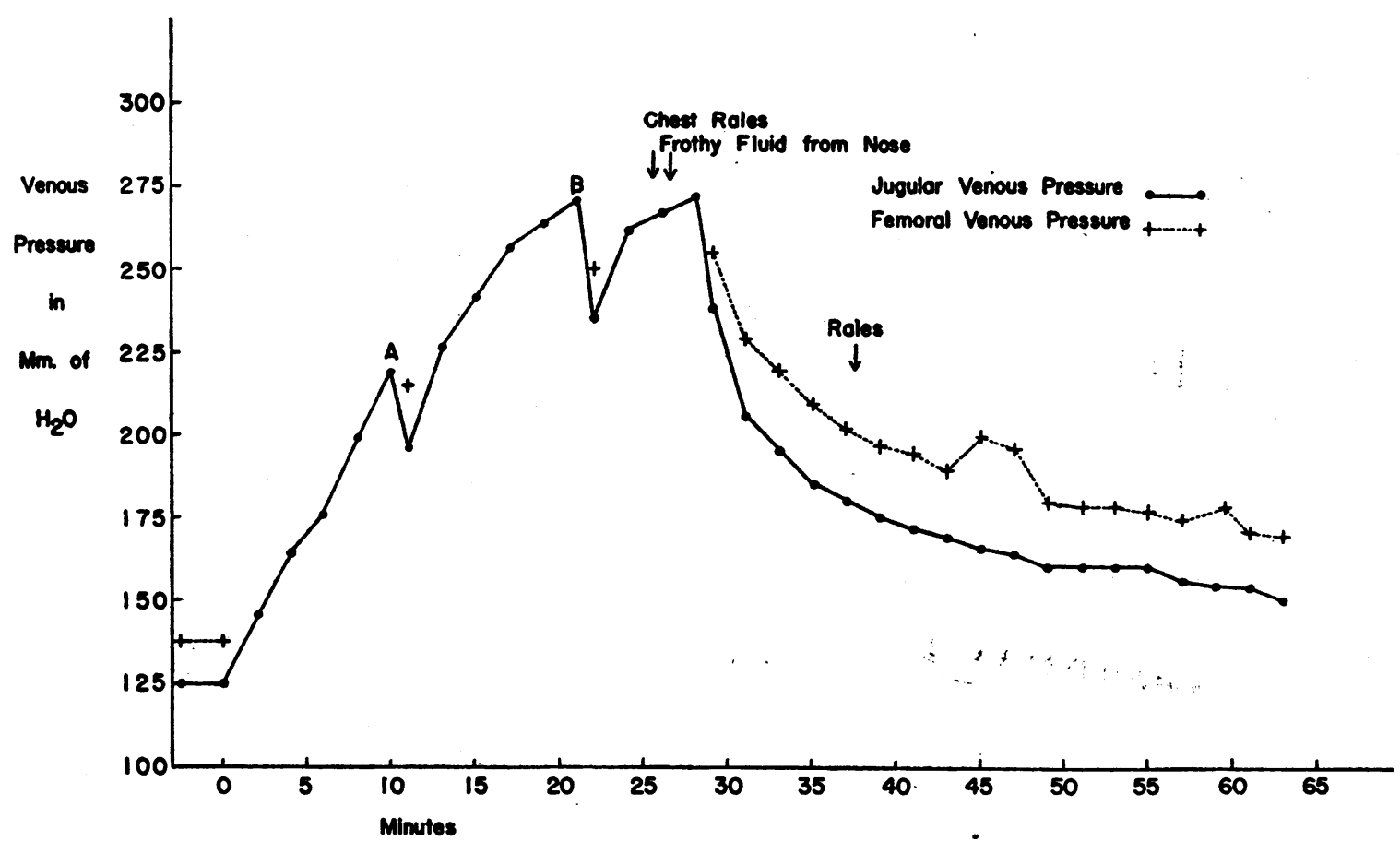

Fig. 11. Represents Infusion with 10 per cent Dextrose in Saline in a Normal Dog

Although this curve is high, it is not unlike other curves obtained with 10 per cent dextrose in saline, in other animals which showed no signs of failure of the left ventricle.

in patients with cardiac failure. In this connection, it is impossible to overstate the importance of a healthy and vigorous heart.

Of considerable interest was the stabilization of the venous pressure during the later part of the experiment. This evidently indicates adjustment of the cardiovascular system to a greatly increased blood volume. The following and perhaps other factors were jointly responsible for this: (1) a continued increase in the cardiac output, (2) an increase in the fluid removed from the vascular system, and (3) an increase in the capacity of the vascular system. The cardiac output probably played a relatively small part, since by far its greatest increase occurred early, and while the venous pressure was still increasing rapidly. On the other hand, during the latter part of some infusions, especially when glucose solutions were used (see Figure 6), it was evident from blood volume studies that fluid was being lost from the intravascular system by way of the kidneys or into the tissues of the body at a very rapid rate. In these experiments, the loss of fluid must have been instrumental in maintaining the venous pressure at a fairly constant level. In others, an increase in the capacity of the vascular system must have been equally effective, since the plasma volume continued to increase steadily. Evidences of this increased capacity were to be found in the dilated peripheral, portal, and pulmonary venous channels, the increased size of the abdomen, liver, spleen, and heart, and congestion of the lungs. Dilatation of the peripheral capillary system, which occurs soon after an infusion is started $(6,7)$, must also have played a role. It should not be assumed from this discussion, however, that the increased venous pressure was anything but helpful, provided it did not rise too high. No doubt this increased the cardiac output and helped to maintain an appropriate distribution of blood.

Whenever, in these experiments, a rapid elevation of peripheral venous pressure occurred during the period when this pressure was usually stable, or pulmonary râles developed (Figures 10 and 11 ), one must assume that the ability of the cardiovascular system to adjust itself to its increased load had been exceeded, and that the elevated 
venous pressure which was previously helpful, now by virtue of an overdistention of the cardiovascular system, constituted a menace. This may be considered in some degree a counterpart of cardiac failure in humans, but certain obvious qualifications need be mentioned. First, the plasma volume was very rapidly increased in our dogs, whereas it is probable that, in humans with cardiac failure, the plasma volume increases much more slowly. Theoretically, it would seem that such a sudden change would produce a maximum stimulation of the heart and at the same time allow a minimum opportunity for an increase and adjustment in the capacity of the vascular system. Second, the concentration of both the plasma proteins and some electrolytes was greatly reduced by this sudden addition of fluid to the blood (8), thus lowering its osmotic pressure, and facilitating the production of pulmonary râles and indistinguishable edema elsewhere. It is interesting to note that pulmonary edema was more apt to develop during glucose infusions, even though this hypertonic solution drew fluid into the vascular system from the interstitial tissues. Apparently, the greatly increased blood volume elevated the hydrostatic pulmonary pressure sufficiently to overcome the osmotic pressure. This would seem to point to the presence of a very high pulmonary capillary pressure in these experiments.

Probably our most interesting observations concerned the pressure relationships which developed during infusion in the general, portal, and pulmonary venous systems. Notably the pressure in the left auricle, which preceding infusion was lower than the general venous pressure, rose very rapidly and to a much higher level than did the general venous pressure. Following infusion, it also fell to normal much more rapidly. This would seem to indicate that the resistance to the flow of blood through the lungs became enormously reduced during infusion, thus allowing a large part of the pulmonary arterial pressure to be transmitted to the venous side of the circuit. Within limits, this increased left auricular pressure would be helpful by increasing the cardiac output. Too great a rise in pressure would eventually lead to pulmonary edema and (unless the infusion were stopped) death. Figures 10 and 11 show two instances in which pulmonary edema occurred in the absence of a greater than usual increase in the peripheral venous pressure. In both of these instances, glucose infusions were used, but this observation was true of saline infusions as well. It is of considerable interest that the pressure in the left auricle can rise so high (Figure 5) without the occurrence of pulmonary râles. In a recent paper dealing with left heart failure in patients, Burwell (9) discussed this same experiment, pointing out how independent of one another the left and right sides of the heart can be in patients.

The portal pressure in two instances was higher than the preinfusion general venous pressure, and rose to a level intermediate between the general venous and left auricular pressures. Two anatomical facts are of interest in this connection. First, the portal system veins have very thick muscular walls, capable, it would seem, of withstanding a considerable increase in pressure. Second, in dogs, circular muscular bands are present in the walls of the hepatic veins. These are so disposed as to be theoretically capable of checking the flow of blood (10), and consequently could effect a storage of blood in the portal system. In fact, this seems to have occurred during infusion since in addition to a marked elevation of the portal pressure, and increase in the size of the spleen in two cases, in all cases marked swelling of the liver and of the abdomen was observed. These facts seem to indicate that the portal, as well as the pulmonary system contained more than its share of the increased plasma volume during infusions. A similar mechanism could operate in patients with congestive heart failure.

\section{SUM MARY}

Rapid infusion in dogs produced:

(1) Congestion in the peripheral, pulmonary, and portal venous systems, evidenced by rises in their venous pressures, swelling of the abdomen, liver, and spleen, and in some cases, pulmonary edema,

(2) An increase in plasma volume and a dilution of the serum proteins,

(3) An increase in the heart rate, heart size, and cardiac output,

(4) Gallop rhythm and systolic murmur,

(5) An increase in oxygen consumption. 
These phenomena and their relationship to congestive failure in humans are discussed. An explanation is offered for the stabilization of the peripheral venous pressure, which takes place during infusion.

The authors wish to thank Dr. C. Sidney Burwell for his helpful suggestions during the progress of these studies, and his aid in presenting their results.

\section{BIBLIOGRAPHY}

1. Swank, R. L., Porter, R. R., and Yeomans, A., The production and study of cardiac failure in thiamindeficient dogs. Am. Heart J., 1941, 22, 154.

2. Trendelenburg, $P$., Verfahren zur Verhinderung der Blutgerinnung bei der Blutdruckschreibung. Arch. f. d. ges. Physiol., 1924, 203, 413.

3. Blalock, A., A rubber mask for determination of oxygen consumption of the dog. J. Lab. and Clin. Med., 1927, 12, 378.

4. Van Slyke, D. D., and Neill, J. M., The determination of gases in blood and other solutions by vacuum extraction and manometric measurement. J. Biol. Chem., 1924, 61, 523.

5. Gibson, J. G., 2nd, and Evans, W. A., Jr., Clinical studies of the blood volume. I. Clinical application of a method employing the azo dye "Evans Blue" and the spectrophotometer. J. Clin. Invest., 1937, 16, 301.

6. Meek, W. J., and Eyster, J. A. E., The effect of plethora and variations in venous pressure on diastolic size and output of the heart. Am. J. Physiol., 1922, 61, 186.

7. Altschule, M. D., and Gilligan, D. R., The effects on the cardiovascular system of fluids administered intravenously in man. II. The dynamics of the circulation. J. Clin. Invest., 1938, 17, 401.

8. Warthen, H. J., Massive intravenous injections. An experimental study. Arch. Surg., 1935, 30, 199.

9. Burwell, C. S., The pathological physiology of the early manifestations of left ventricular failure. Ann. Int. Med., 1942, 16, 104.

10. Arey, L. B., Throttling veins in the livers of certain mammals. Anat. Rec., 1941, 81, 21. 